\title{
Desigualdades que atraviesan fronteras. Procesos de inserción laboral de mujeres haitianas al mercado de trabajo en Chile
}

\author{
Inequalities that cross borders. \\ Processes of labor market integration of haitian women in Chile \\ IsABel Bustamante Cifuentes ${ }^{\mathrm{a}}$ \\ aTrabajadora Social. Máster en Antropología Urbana, UAHC, Chile. \\ Máster en Política Social, Trabajo y Bienestar, UAB, España \\ $\square$ isabelbustamante85@gmail.com
}

\begin{abstract}
RESUMEN
El estudio explora la realidad laboral y social que las mujeres inmigrantes haitianas están viviendo en Chile y específicamente describe cómo se desarrolla su experiencia de inserción laboral en el mercado del trabajo chileno. El trabajo remunerado como único espacio de "integración social" para la población migrante, se convierte en un predictor tanto del bienestar individual como social de la persona y en el caso de las mujeres, se añade la interacción de factores de desigualdad distintos que sus pares hombres. El enfoque es de carácter cualitativo y utiliza el estudio de casos como su metodología de base. Entre sus conclusiones, se propone incorporar acciones concretas en las políticas públicas que permitan disminuir las barreras y riesgos en el campo del trabajo, a los que se exponen cotidianamente estas mujeres migrantes y sus familias en el Chile actual.
\end{abstract}

PALABRAS CLAVE: Mercado de trabajo, mujeres inmigrantes, inserción laboral, factores de desigualdad.

\begin{abstract}
The investigation explores the social-work situation that Haitian immigrant women are living in Chile and specifically describes how their experience of labor insertion develops in the Chilean labor market. Paid work, considered the only space of "social integration" for the migrant population, becomes a predictor for both the individual and social well-being of the person, and regarding to women we have to add the interaction of different inequality factors which are not the same as their peers' men. The approach is qualitative in nature and uses


case studies as its basic methodology. Among its conclusions, it is proposed to incorporate specific actions in public policies that allow reducing the barriers and risks in the work field, which migrant women and their families are daily exposed nowadays in Chile.

KEY WORDS: Labor market, immigrant women, labor insertion, inequality factors.

\section{INTRODUCCION}

Las mujeres son las protagonistas del proceso migratorio actual, en un contexto global de constante dinamismo y transformación, sus experiencias se desarrollan en espacios locales específicos alrededor de todo el mundo. Esta progresiva tendencia hacia la feminización de los flujos migratorios, responde a varios mecanismos y sucesos que han sido ampliamente abordados por diversas autoras (Hochschild, 2001; Sassen, 2003; Yuval-Davis, 2006; Anthias, 2012). A modo de ejemplo, en Europa, la situación estaría respondiendo a una "crisis del cuidado" que está siendo visiblemente cubierta por mujeres trabajadoras y migrantes del mal llamado "tercer mundo", lo cual deriva en la aparición de una serie de estrategias y configuraciones que se despliegan en el espacio transnacional. Por otro lado, en Latinoamérica, la situación obedece a otros factores y más que tratarse de una "crisis de los cuidados", la movilidad de las mujeres a nivel intrarregional es una estrategia de supervivencia frente a la inestabilidad y crisis económica, social y política de sus países de origen. Atravesando fronteras en búsqueda de oportunidades laborales, las mujeres deben enfrentar la creciente informalidad del mercado de trabajo en Chile, el cual se desarrolla sin límites potenciando altos niveles de precariedad, segmentación y desigualdad, absorbiendo a una parte mucho mayor de la población económicamente activa que en los países europeos (Thayer, 2011; Stefoni 2011; Acosta, 2011; Novick, 2012; Cárdenas et al. 2014; Magliano, 2015).

De esta manera, la nueva realidad migratoria que se configura en Chile, es un hecho observable cotidianamente, tan sólo basta con recorrer la ciudad y darnos cuenta de esa diversidad indiscutible que atiborra las calles, sin embargo aunque esto sea evidente, parece no tener la suficiente relevancia a nivel de diseño e implementación de Políticas Públicas. Hoy, quienes toman las decisiones en Chile, proponen cada vez menos oportunidades de desarrollo a una población que aumenta y la ausencia de una política migratoria concreta, profundiza la falta de perspectiva en la materia y por ende la marginación de las personas migrantes.

Los flujos migratorios provenientes de la región caribeña puntualmente Haití y República Dominicana, han adquirido mayor notoriedad en los últimos años y hasta el momento, existen pocas referencias que muestren cuál es la realidad laboral que viven particularmente las mujeres en este colectivo. Los estudios sobre migración, mercado de trabajo y género en el país, se han centrado en conocer la experiencia de los grupos migratorios más importantes en términos demográficos como la comunidad peruana por ejemplo olvidando a otras 
"minorías" y, por otro lado, han relevado el hecho de que las mujeres migrantes cumplen funciones mayoritariamente reproductivas y productivas, aquí cabría preguntarse si esta situación es extrapolable a "otras" con características y condiciones diferentes.

Al respecto es importante recalcar que la incorporación de la categoría de género en el estudio de los movimientos migratorios, no puede ser considerada de manera aislada, ya que el comportamiento de los desplazamientos actuales muestran cómo este componente genera una serie de vulneraciones y desigualdades reproducidas especialmente en el mercado de trabajo, potenciando nuevas formas de segmentación y discriminación laboral que en el caso de "mujeres haitianas", implica también criterios raciales y étnicos. A partir de esta afirmación surge entonces, la necesidad de indagar cómo se desarrolla el proceso de inserción y trayectoria laboral de estas mujeres en palabras de sus protagonistas, a través del estudio de casos se espera tener una aproximación a esta realidad y establecer así, mayores antecedentes a una situación poco estudiada en Chile pero urgente de atender. Comprender de qué manera enfrentan la precariedad del empleo y las diversas consecuencias que ello contrae en su experiencia migratoria, significa repensar la "intervención social" en esta área y con este colectivo en particular.

\section{LAS MIGRACIONES FEMENINAS EN CHILE: FLUJOS Y PROCESOS DE INSERCIÓN LABORAL}

En Latinoamérica y Chile particularmente, la transnacionalización del trabajo doméstico obedece a fuertes transformaciones económicas que producen un movimiento masivo de personas, esto moldea los mercados laborales manifestándose tres grandes sucesos: la sistemática incorporación de mujeres inmigrantes a la oferta de empleos precarios, la visibilización de lo racial versus lo nacional (que se suman a la clase y al género) y por último la urgencia por parte de organismos internacionales en fiscalizar y exigir a los Estados una mínima garantía de derechos laborales (Stefoni \& Fernández, 2011, p. 46).

Al respecto, en palabras de Sassen (2003) "la categoría de mujeres migrantes consta de muchos componentes concretos que van desde condiciones de situación de reserva hasta la completa participación en el empleo asalariado" (Sassen, 2003, p. 144), es decir, se refuerza aquí la idea de que las mujeres migrantes serían una fuente de mano de obra potencial y reservada, para la subsistencia de la nueva industrialización, esto en razón de la desprotección permitida por legislaciones restrictivas sobre la inmigración y la permisividad arbitraria que tienen las industrias exportadoras, sin fronteras para decidir instalarse en países donde su funcionamiento remite menores costos garantizando su sostenimiento en el competitivo mercado actual. De esta manera, se imponen condiciones que posibilitan el ingreso de capitales extranjeros, esto por ejemplo se traduce en la flexibilización del mercado de trabajo, la reducción de la protección social y el mantenimiento solapado de una economía informal que permite a las inmigrantes 
trabajar como indocumentadas, sin tener por ello acceso a la más mínima garantía de derechos y ciudadanía.

En este sentido, la feminización de la mano de obra asalariada es un hecho histórico e innegable, donde la incorporación de las mujeres inmigrantes permite fortalecer nuevas formas de organización del proceso de trabajo, puesto a que se imponen condiciones de precariedad que son fácilmente aceptadas por este colectivo. La mayoría de las aportaciones teóricas que existen para definir características de la relación entre mercado de trabajo, migración y género en Chile, vienen de estudios realizados sobre la masiva inserción de las mujeres migrantes al trabajo doméstico, la formación de pequeños emprendimientos ligados al comercio y actividades productivas o la incorporación sistemática de mujeres en el circuito informal de la economía local. Aquí se ha constatado que las migrantes recorren un largo camino de reconocimiento al interior de sus espacios laborales y el éxito de ello depende, del nivel de capital social que posean, siendo esto la suma del capital cultural, las redes sociales y el contexto normativo vigente (Cárdenas, et al, 2014). Dentro de este orden de ideas, la dinámica de relaciones laborales en el país, esboza una evidente segmentación horizontal (fracciones del mercado del trabajo fuertemente feminizados) y vertical, es decir, las mujeres suelen ocupar posiciones de poder relativamente inferiores en una determinada estructura social (Brega et al. 2015).

Por otra parte, son escasos aun los aportes académicos sobre el flujo migratorio haitiano hacia Chile. Lo que existe, son una serie de datos estadísticos oficiales sobre el número de población migrante, origen y características generales de la misma. Dicha situación, nos encamina hacia la posibilidad de explorar esta realidad con apertura, reconociendo que las experiencias de las mujeres en los procesos migratorios son cualitativamente diferentes a las de los hombres; así como también heterogéneas entre el mismo colectivo femenino, por lo cual su estudio requiere de un especial tratamiento. La presencia haitiana ha provocado expectación y conflicto en la sociedad chilena, acostumbrada a una migración de carácter andina y no afrodescendiente. Esto deriva en situaciones de racismo y discriminación que habilitan y potencian la exclusión y segmentación laboral.

Según cifras del Departamento de Extranjería y Migración (2015), el 82\% de las visas otorgadas a personas haitianas son de trabajo y su ingreso exhibe un aumento en proyección. Esta tendencia de movilidad, se ha denominado como "nueva inmigración" y la integran colectivos provenientes de República Dominicana, Haití y Colombia. En el caso de Haití, las razones atribuibles a su arribo en Chile, serían tres según los trabajos de Hidalgo (2014) y Rojas et al (2015); primero la imagen de un país que se proyecta estable en el ámbito económico y político, así como su crecimiento, la reducción de la pobreza y el establecimiento de múltiples acuerdos económicos producen un efecto de atracción, que se ha estado visibilizando en las últimas décadas, segundo la intensificación de medidas restrictivas sobre la migración en países que eran normalmente el destino principal como 
Canadá, Francia, República Dominicana, España y Estados Unidos, producto de las crisis económicas que estos viven en los últimos años (Hidalgo, 2014) y el establecimiento de regulaciones que incluso han sido criticadas por contravenir el derecho internacional, como es el caso de República Dominicana, que aprueba constitucionalmente y de forma retroactiva, desconocer la nacionalidad de personas haitianas que hayan nacido en un contexto de "ilegalidad". Una tercera razón estaría dada por el recrudecimiento de las condiciones de pobreza, crisis sanitaria e inestabilidad que genera el terremoto del 2010 en Haití, sumado a la dificultad histórica en la instauración de un régimen democrático (Rojas et al. 2015).

El Departamento de Extranjería y Migración (2015) reconoce tres flujos o perfiles migratorios en el colectivo haitiano; el flujo "A" conformado por migrantes con mayor capital cultural, económico y social y redes de apoyo en el país de destino, quienes aspiran a establecerse en países como Estados Unidos, Francia o Canadá; un flujo "B" compuesto por migrantes con ciertos recursos disponibles, aspirantes a una mejor calidad de vida pero con escasas redes de apoyo o contacto en los países del norte, razón por la cual buscan alternativas para finalizar su periplo, estableciéndose en otros lugares como Brasil o Chile, con ello pueden reunir los recursos y la experiencia suficiente para llegar a su destino final en el "primer mundo"; por último un flujo "C" constituido por migrantes precarizados, aspirantes a mejorar sus condiciones de subsistencia, su desplazamiento se vincula con la migración rural histórica, relacionada a la industria azucarera en República Dominicana. Tras esta clasificación afirma el DEM (2015), Chile pasa a ser referente migratorio para los flujos "C" y "B" (p: 8).

\section{METODOLOGIA}

Con el objeto de conocer cómo se desarrolla el proceso de inserción y trayectoria laboral de mujeres haitianas en la capital de Chile, se realizó un estudio de casos que contempla la realización de cinco entrevistas a mujeres haitianas. Este tipo de diseño metodológico que permite profundizar en el estudio de un objeto de investigación donde aún hay aspectos escasamente estudiados. Con un énfasis metodológico de carácter descriptivo, se opta por considerar a un número reducido de mujeres con características similares y analizar la información discursiva de sus relatos. Es necesario señalar que esta investigación, busca explorar las características y particularidades de la realidad de inserción laboral que viven las mujeres trabajadoras inmigrantes haitianas en Chile y permite comprender cómo se relaciona esta experiencia con sus procesos y proyectos migratorios específicos en el caso de las personas participantes en estudio.

En los estudios de caso, la teoría cumple un papel fundamental para la selección de las unidades, de acuerdo a esto, se decide construir una tipología teórica y parrilla tipológica (Verd \& Lozares, 2016). A través de un proceso extenso de revisión y 
Tabla 1. Parrilla Tipológica construida a partir de los factores de edad, tiempo de estancia en Chile y manejo del idioma español de "mujeres haitianas".

\begin{tabular}{|l|c|c|c|}
\hline $\begin{array}{l}\text { Manejo del } \\
\text { español }\end{array}$ & Tiempo de estancia & $\begin{array}{c}\text { Mujeres jóvenes } \\
\text { (20 a } 35 \text { años) }\end{array}$ & $\begin{array}{c}\text { Mujeres adultas } \\
\text { (36 a 55 años) }\end{array}$ \\
\hline \multirow{2}{*}{$\begin{array}{l}\text { Entiende/ puede } \\
\text { expresarse }\end{array}$} & Menos de 2 años & Caso 1 y 4 & Caso 2, 3 y 5 \\
\cline { 2 - 4 } & Más de dos años & No aplica & No aplica \\
\hline \multirow{2}{*}{$\begin{array}{l}\text { No entiende/ no } \\
\text { puede expresarse }\end{array}$} & Menos de 2 años & No aplica & No aplica \\
\cline { 2 - 4 } & Más de dos años & No aplica & No aplica \\
\cline { 2 - 4 } & Más de dos años & No aplica & No aplica \\
\hline
\end{tabular}

Fuente: adaptación de Verd y Lozares (2016, p. 131).

discusión teórica, se destacan algunos aspectos que orientan la definición de criterios de uniformidad como la edad, tiempo de permanencia en Chile y manejo del español.

Respecto a las técnicas de obtención de los datos, se decide realizar entrevistas de tipo semi-estructurada o dirigida y en base a la información aquí obtenida, efectuar un análisis de contenidos temático. Es importante recalcar que las entrevistas realizadas son meramente exploratorias y la selección, se ha hecho en base a condiciones de tiempo y accesibilidad, tratando de lograr la máxima dispersión posible de perfiles. La elección del tipo de entrevista y las temáticas puntuales que se abordaron, responden a los conocimientos que proporciona la discusión teórica realizada y los objetivos de indagación propuestos. Esta pauta, estuvo orientada a conocer las vivencias y experiencias significativas de las entrevistadas en relación a lo laboral y sus decisiones migratorias.

Una vez transformada la información en texto se comienza a desarrollar el análisis, en este paso fue importante asegurar la objetividad del procedimiento y establecer reglas o criterios que guiaron la exclusión e inclusión de contenidos a analizar, para ello se elabora una "tabla de descriptores" de las categorías teóricas predeterminadas, señalando los resultados que se alcanzaron mediante las sucesivas observaciones efectuadas en este contexto de investigación. Luego de la asignación de códigos, se procede a agrupar estos en un aspecto que está a la base de dicha relación, de esta manera el conjunto de datos codificados se encasillan en una categoría analítica (Cáceres, 2003).

\section{RESULTADOS}

\section{Mujeres haitianas: experiencas de inserción laboral en Chile}

En primera instancia hemos de definir el objeto de análisis, que se compone del cuerpo total de información obtenida a partir de la aplicación de cinco entrevistas a "mujeres haitianas" entre los meses de julio y agosto del año 2017. Las mujeres residen en las comunas 
de Estación Central, Cerro Navia y Santiago centro, todas se encuentran en situación irregular en el país y sin trabajo estable, sus formaciones u oficios son variados al igual que sus edades.

Es preciso indicar, que los relatos proporcionados por las mujeres fueron de corta extensión y de difícil comprensión debido al bajo nivel de español. Esta situación complejiza el proceso de análisis, siendo necesario seleccionar unidades de registro compuestas en algunos casos, de preguntas y respuestas con el objeto de contextualizar las frases pronunciadas por las mujeres, ya que sin esto no sería posible entender el sentido de los extractos. Por otra parte, la barrera idiomática también generó dificultades en la búsqueda de los perfiles, haciendo de este proceso un trabajo laborioso, por lo cual se decidió integrar la participación de un interlocutor nativo que actuara como intérprete en el momento de la entrevista y el primer contacto.

Las mujeres haitianas que participaron de esta iniciativa tienen una característica común, la mayoría exhibe poca o nula experiencia laboral en Chile. En el siguiente cuadro se observan la cantidad de entrevistadas, según edad, tiempo de estancia en Chile y manejo del español:

Tabla 2. Tipología de mujeres entrevistadas.

\begin{tabular}{|l|c|c|c|}
\hline Casos & Edad & $\begin{array}{c}\text { Tiempo de } \\
\text { estancia }\end{array}$ & $\begin{array}{c}\text { Manejo del } \\
\text { español }\end{array}$ \\
\hline Caso 1 & 29 años & 1 año 6 meses & $\begin{array}{c}\text { Entiende/ puede } \\
\text { expresarse }\end{array}$ \\
\hline Caso 2 & 49 años & 1 año y 2 meses & $\begin{array}{c}\text { Entiende/ puede } \\
\text { expresarse }\end{array}$ \\
\hline Caso 3 & 42 años & 6 meses & $\begin{array}{c}\text { No entiende/ no } \\
\text { puede expresarse }\end{array}$ \\
\hline Caso 4 & 30 años & 2 meses & $\begin{array}{c}\text { No entiende/no } \\
\text { puede expresarse }\end{array}$ \\
\hline Caso 5 & 50 años & 5 meses & $\begin{array}{c}\text { Entiende/ puede } \\
\text { expresarse }\end{array}$ \\
\hline
\end{tabular}

A través de un intensivo y sistemático trabajo de codificación, categorización, interpretación y análisis, se elaboran matrices comparativas. Este diálogo pone en evidencia los primeros resultados, la emergencia de subcategorías inductivas que contrastan con aquellas teóricas delimitadas previamente, estas se indican en la Tabla 3.

En este recuadro, es posible evidenciar empíricamente, cómo se desarrolla el proceso de inserción y trayectoria laboral de las entrevistadas en la región metropolitana, dando cuenta de ciertas particularidades con las que este se desarrolla, para graficar las relaciones que se producen en la interacción de distintos aspectos señalados por las mujeres, sobre sus experiencias de inserción al mercado de trabajo, es que se decide representar los hallazgos a través de diagramas de flujo. 
Tabla 3. Categorías y subcategorías de análisis.

\begin{tabular}{|c|c|c|}
\hline CATEGORÍAS & Subcategorías inductivas & Subcategorías teóricas \\
\hline $\begin{array}{l}\text { Proyecto migratorio } \\
\text { de las "mujeres } \\
\text { haitianas" }\end{array}$ & $\begin{array}{c}\text { a) Inseguridad de Haití y mejores } \\
\text { condiciones de vida para sus familias } \\
\text { motivan la salida en búsqueda de } \\
\text { trabajo. } \\
\text { b) Facilidades de ingreso al país } \\
\text { tienen un efecto de atracción para las } \\
\text { mujeres haitianas } \\
\text { c) Residentes haitianos en Chile } \\
\text { proporcionan información sobre el } \\
\text { mercado de trabajo } \\
\text { d) Alta inversión de recursos } \\
\text { financieros para solventar el ingreso } \\
\text { al país } \\
\text { e) Proyecto migratorio se extiende a } \\
\text { otros países ante escasas } \\
\text { oportunidades laborales }\end{array}$ & $\begin{array}{l}\text { a) Motivaciones } \\
\text { económicas } \\
\text { b) Experiencia de } \\
\text { migración previa } \\
\text { c) Proyecto migratorio } \\
\text { transitorio }\end{array}$ \\
\hline $\begin{array}{l}\text { Inserción laboral de } \\
\text { "mujeres haitianas" } \\
\text { al mercado de } \\
\text { trabajo en Santiago }\end{array}$ & $\begin{array}{l}\text { a) Irregularidad migratoria impide } \\
\text { acceder a mejores puestos de trabajo } \\
\text { b) Red de apoyo compuesta por } \\
\text { familiares y amistades } \\
\text { c) Búsqueda de empleo se realiza con } \\
\text { poca orientación d) Fundaciones } \\
\text { eclesiásticas operan como oficinas de } \\
\text { colocación de empleo } \\
\text { e) Inserción laboral en trabajos de } \\
\text { baja cualificación y actividades por } \\
\text { cuenta propia }\end{array}$ & $\begin{array}{l}\text { a) Redes de contacto } \\
\text { b) Nichos laborales } \\
\text { precarios } \\
\text { c) Economía informal }\end{array}$ \\
\hline $\begin{array}{l}\text { Trayectoria laboral } \\
\text { de las "mujeres } \\
\text { haitianas" }\end{array}$ & $\begin{array}{l}\text { a) Períodos de cesantía e inestabilidad } \\
\text { prolongados } \\
\text { b) Contratación fraudulenta o } \\
\text { irregular } \\
\text { c) Ocupación por cuenta propia para } \\
\text { suplir la falta de empleo e ingresos } \\
\text { d) Salarios bajos y exceso de trabajo } \\
\text { e) Vulneración de derechos y maltrato } \\
\text { laboral }\end{array}$ & $\begin{array}{l}\text { a) Irregularidad laboral } \\
\text { b) Segmentación laboral } \\
\text { c) Condiciones } \\
\text { laborales }\end{array}$ \\
\hline $\begin{array}{l}\text { Factores de } \\
\text { desigualdad en el } \\
\text { proceso de } \\
\text { inserción y } \\
\text { trayectoria laboral } \\
\text { de "mujeres } \\
\text { haitianas" }\end{array}$ & $\begin{array}{l}\text { a) Nacionalidad } \\
\text { b) Irregularidad migratoria } \\
\text { c) Habitacional } \\
\text { d) Idioma } \\
\text { e) Económicas/ingresos }\end{array}$ & $\begin{array}{l}\text { a) Género } \\
\text { b) Raciales/étnicas } \\
\text { c) Clase }\end{array}$ \\
\hline
\end{tabular}

Se observa que las "mujeres haitianas" en general exhiben una situación ocupacional previa relativamente estable, muchas de ellas llevan varios años trabajando en distintas actividades tanto en Haití como en República Dominicana, no obstante la sensación de inseguridad debido a la compleja realidad política, económica y social que vive el país, entregar a sus familias una mejor calidad de vida o lograr que sus hijos e hijas crezcan en un lugar con más expectativas de desarrollo, motivan la decisión de emigrar en búsqueda de trabajo, 


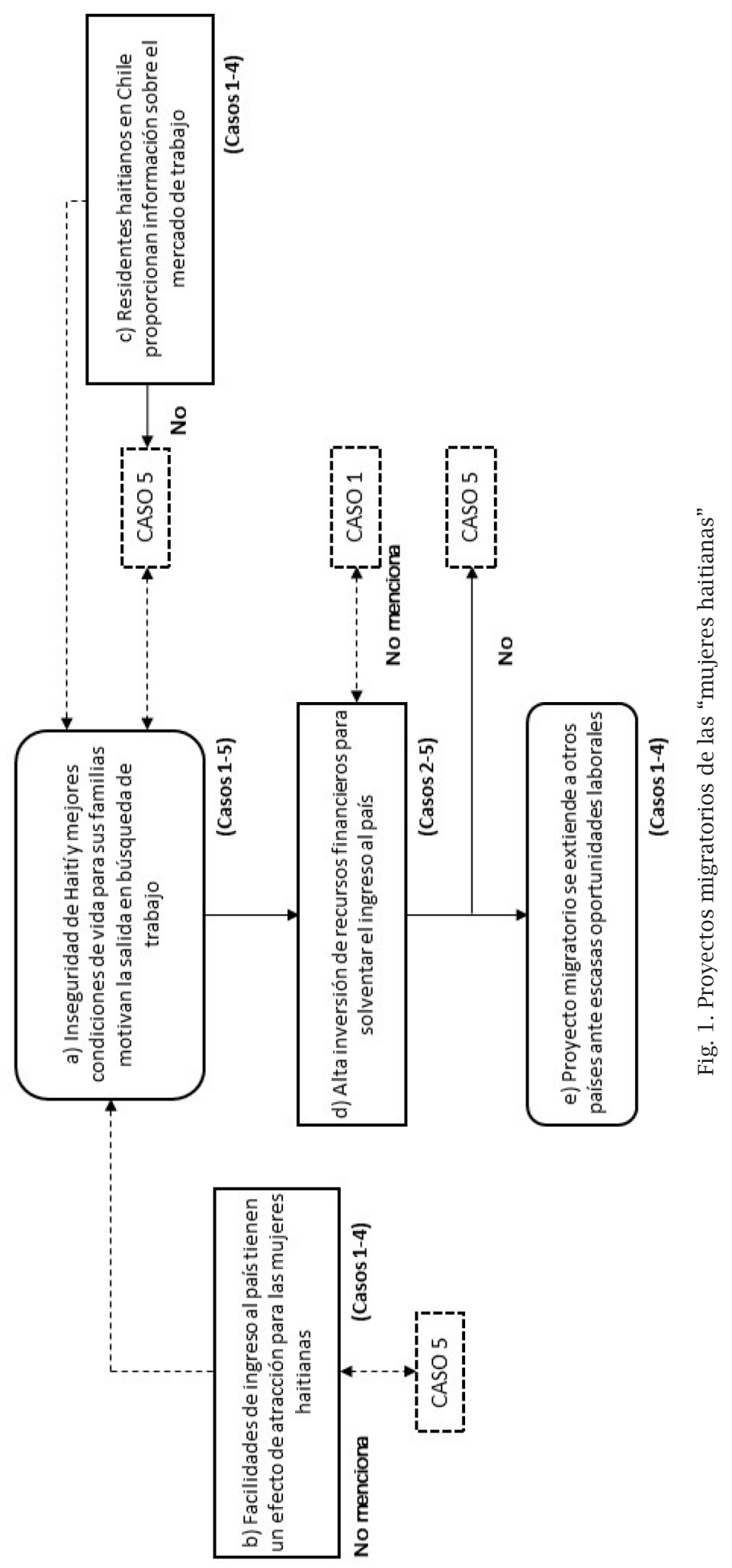


este es el punto de partida del proyecto migratorio. Chile aparece como una posibilidad en el mapa por dos factores principales, primero están las facilidades de ingreso al país que ejercen un fuerte efecto de atracción para ellas, algunas de estas mujeres intentan residir en otros países como Estados Unidos o tienen experiencias migratorias previas en el país vecino, lo cierto es que, ante el duro control de las fronteras norteamericanas y el recrudecimiento de la legislación migratoria en República Dominicana, el fácil ingreso a Chile en condición de turista lo convierten en un destino preferencial dentro de su travesía migratoria. Por otro lado, se observa que la información sobre la realidad laboral del país, es proporcionada en casi todos los casos por connacionales haitianos que se encuentran trabajando en Chile, estas personas (que pueden ser familiares, amigos o "conocidos") cuentan a las mujeres sus experiencias de viaje y señalan la presencia de una multiplicidad de oportunidades laborales con altos ingresos, algunos incluso aprovechan este conocimiento para cobrar por gestionar el ingreso al país. Estudios anteriores en Chile (Hidalgo, 2014; Rojas 2015; Valenzuela et al. 2014), señalan que los inmigrantes haitianos tienen mejores expectativas de inserción laboral que las mujeres, ya que son requeridos en sectores donde normalmente tienen posibilidades de obtener un contrato (como grandes empresas gasolineras por ejemplo), o al menos establecer un acuerdo de palabra que ampara la relación contractual, resolviéndose la situación migratoria a través de un contrato ficticio (como en el sector de la construcción), esta disonancia de trayectorias laborales entre hombres y mujeres -que tampoco es privilegiada o mejor- produce que residentes haitianos promuevan una imagen sobre el mercado de trabajo basada en sus experiencias, la cual no es extrapolable a las mujeres. Numerosos estudios comprueban (Martínez Buján, 2011; Parella, 2003-2007; Pérez Orozco, 2006; Sassen, 2003; Stefoni \& Fernández, 2011), que las condiciones de las mujeres en el mercado de trabajo, son cualitativamente diferentes a las de los hombres. Es importante, destacar en este ámbito la experiencia del Caso 5, quien viaja a Chile instada por sus amigas y en quince días encuentra un empleo como trabajadora doméstica, aunque luego es despedida, es el único caso que se manifiesta conforme con su desempeño laboral, este antecedente es relevante ya que marca la diferencia con los otros casos y muestra como las mujeres aportan información concreta y real basada en sus propias experiencias.

Cuando la decisión de migrar a Chile está tomada, invierten una alta suma de dinero para viajar al país, el costo del boleto de avión fluctúa entre los mil y los mil cuatrocientos dólares, a esto se agregan una cantidad importante de recursos que comprueban la capacidad de solvencia y garantizan el ingreso al país. En total necesitan entre tres mil y tres mil quinientos dólares para cruzar la frontera. Este costo elevado produce en algunos casos endeudamiento o una importante disminución en los recursos que luego destinan para gestionar su establecimiento en el país, cuando alguna de ellas paga por servicios ilícitos en este ámbito como la compra de una carta de invitación o la gestión de una reservación de hotel. La situación se complejiza aún más ante las escasas oportunidades laborales e ingresos bajos, que no permiten pagar este dinero "adeudado" provocando mayor empobrecimiento 
y una especie de detención obligada en el país, ya que sin estos recursos no pueden volver a Haití o trasladarse a otros países teniendo que trabajar meses para reunir nuevamente este dinero y emprender su salida a otros destinos. Finalmente, la precariedad de la vida a la que se enfrentan en su intento por permanecer en el país, cambian el proyecto inicial y comienzan a evaluar otras posibilidades para concretar sus objetivos, como seguir su trayecto a otros países de Latinoamérica o regresar al país de origen.

La inserción laboral de "mujeres haitianas" en trabajos de baja cualificación, es un proceso complejo e implica una interacción entre diversos elementos que potencian su desarrollo y consolidan nichos laborales exclusivos para mujeres migrantes. En el diagrama se observa que esta situación tiene como punto de partida la irregularidad migratoria. Conseguir un contrato de trabajo y en consecuencia el visado que legalmente habilita a la persona para trabajar en el país, genera un círculo en el que estas mujeres permanecen atrapadas por largo periodo sin poder acceder a mejores puestos. Sin "papeles" como ellas mencionan, es más difícil encontrar empleo y sus posibilidades se reducen a aceptar ocupaciones precarias e informales, siendo imposible romper con esta dinámica. Según la discusión teórica realizada, el éxito en las estrategias desplegadas para encontrar un empleo, depende del nivel de capital social que las "mujeres haitianas" posean, esto comprende la suma del capital cultural, las redes sociales y el contexto normativo vigente (Cárdenas et al. 2014). Al respecto, se aprecia que la red de apoyo se conforma principalmente por familiares y algunas amistades connacionales, este es el único soporte con el que cuentan para gestionar la búsqueda de empleo y solventar la falta de ingresos, el rol del Estado en este ámbito es absolutamente ausente. Es así que las mujeres realizan un recorrido por la ciudad, encontrándose a veces en lugares desconocidos. En los Casos 3 y 5, quienes exhiben una red más fortalecida y compuesta por otras mujeres en sus mismas condiciones, se advierte que su experiencia laboral ha estado mucho más clara en el tiempo en términos de decisiones y obtención de un empleo, pero esto tampoco cambia la tendencia de inserción que se expresa en el diagrama.

Por otro lado en esta dinámica, las entrevistadas señalan que organizaciones eclesiásticas lugares en los que asisten a clases de español, "se ayuda a las personas a encontrar trabajo". Aquí se constata que estas instituciones operan como oficinas de colocación de empleo. Varias mujeres con las que se conversó en las inmediaciones de este lugar asistían con la esperanza de que se les proporcionara un trabajo y la mayoría de los casos aquí analizados exponen esta misma situación. En este contexto, destaca la experiencia del Caso 1 quien es contratada por una parroquia y Fundación a la que asiste en búsqueda de orientación y aprendizaje del idioma. Una vez cumplidos los tres meses de "prueba" la despiden negándole la posibilidad de continuar por no tener permiso de trabajo, situación que es conocida para ellos. Es importante indicar que las circunstancias aquí descritas corresponden a esta realidad en particular y demuestran dos cosas, por una parte la falta de atención e intervención pública y por otra, la marcada presencia del tercer sector abordando especialmente la llegada de "mujeres haitianas", sin fiscalización ni posterior seguimiento de sus acciones. La 
I. Bustamante

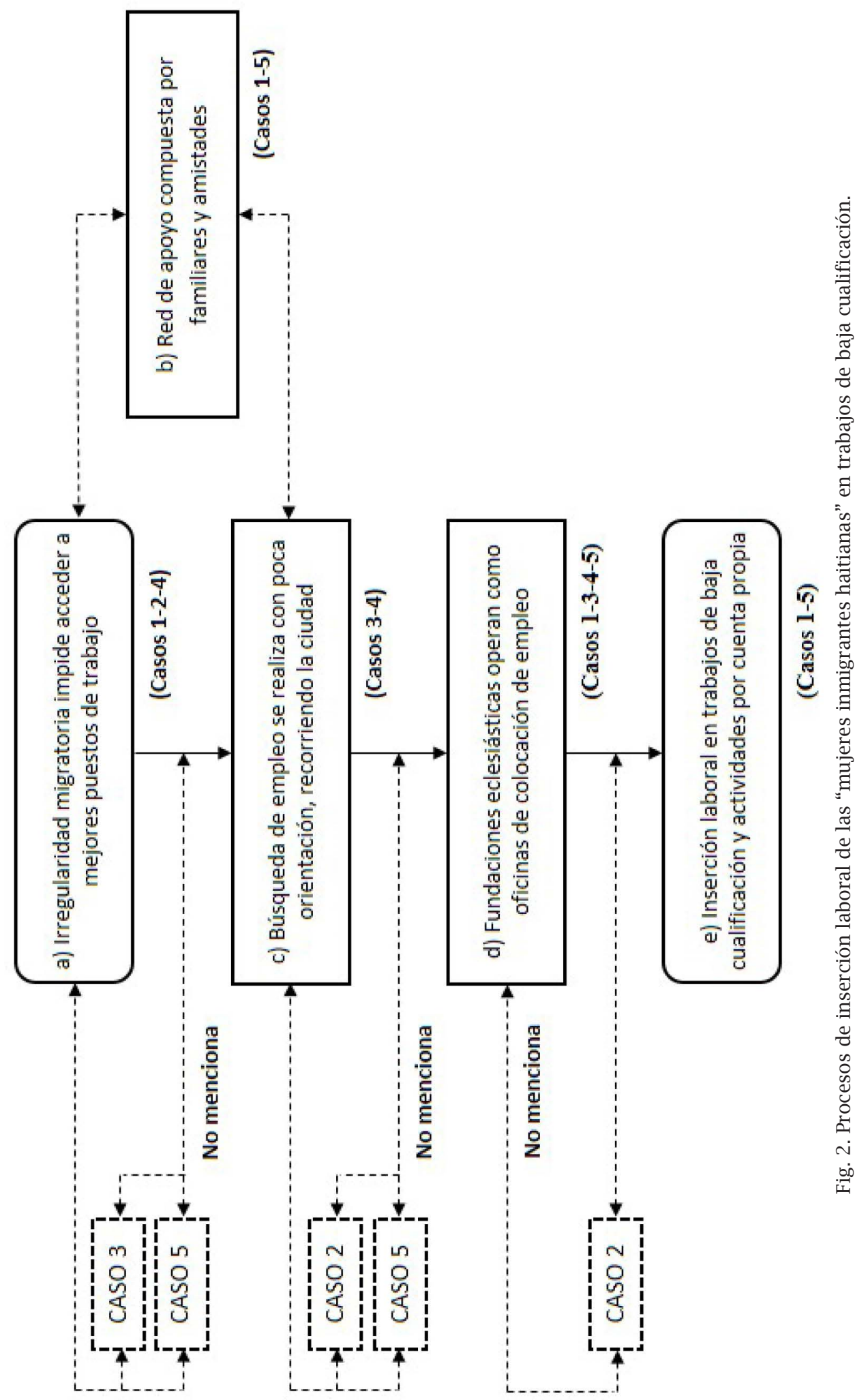


proliferación de instituciones que operan con un foco asistencial y no de derechos es riesgosa, puesto a que mantiene y fortalece la formación de un segmento ocupacional destinado a las mujeres inmigrantes, conformado por una amplia oferta de empleos precarios, limitando el destino laboral de estas personas.

Antes de describir los resultados, es necesario puntualizar que cada una de las experiencias en el ámbito laboral de estas mujeres es distinta y única, sin embargo en esta indagación se ha optado por describir las particularidades o puntos comunes que caracterizan la trayectoria laboral de "mujeres haitianas" en un mercado de trabajo también especial como es el de Chile. En primer lugar, se observa en el diagrama que este proceso comienza con largos periodos de cesantía e inestabilidad laboral los cuales pueden llegar hasta los seis meses; las mujeres debido a la necesidad de regularizar su situación migratoria, obtener ingresos para mantener el alto costo de la vida en Chile y además asegurar el envío de remesas, despliegan una serie de estrategias y pueden llegar a ser víctimas de situaciones como la contratación fraudulenta o engañosa por parte de empresas privadas y otros organismos. Cabe destacar que de las cinco mujeres entrevistadas tres tienen experiencia laboral, no obstante una de ellas evade referirse al trabajo que desempeño como empleada doméstica en una casa particular y los otros dos casos, muestran distintas formas de recorrer el camino de desempeñarse laboralmente en Chile. Por un lado el Caso 1, trabaja como personal de aseo en una empresa contratista (del rubro construcción en obras menores). Luego de cuatro meses sin trabajo, le ofrecen un contrato que resulta ser fraudulento y con el cual no puede obtener el visado, siendo rechazada su solicitud en extranjería, posteriormente permanece desocupada y vuelve a ser contratada con la promesa de un contrato indefinido que no es tal, ya que al culminar los tres meses permitidos legalmente antes de que se efectué el trámite de regularización, le anuncian a sabiendas de este hecho, que no puede continuar trabajando. Por otro lado el Caso 3, compra por el valor de sesenta mil pesos un contrato falso para regularizar su situación migratoria y aún está a la espera del visado, se desempeña en el sector agrícola por un mes, pero debido a un accidente laboral y malas condiciones, abandona esta actividad y finalmente opta por emplearse en actividades por cuenta propia con otras mujeres también haitianas, gestionando en conjunto la falta de empleo.

Estos casos, según la literatura de investigación en el área son usuales en el país; la contratación engañosa de trabajadores migrantes puede estar constituyendo una práctica habitual que a la luz de legislaciones migratorias restrictivas como en Chile, aumentan la desprotección social y permiten la instauración de infracciones solapadas como "acuerdos de palabra". Por otro lado, las "mujeres haitianas" sea la vía asalariada o no, se están desempeñando en empleos de mala calidad, con salarios bajos y muy variables, que no corresponden al Ingreso Mínimo Mensual legal en el país, además cumplen múltiples funciones solapándose el trabajo de hogar con el de cuidados, algo que Martínez Bujan (2010) denomina como "nuevo servicio de hogar" o "servicio doméstico del envejecimiento", aquí las mujeres migrantes no distinguen diferencia y usualmente el volumen de trabajo es 


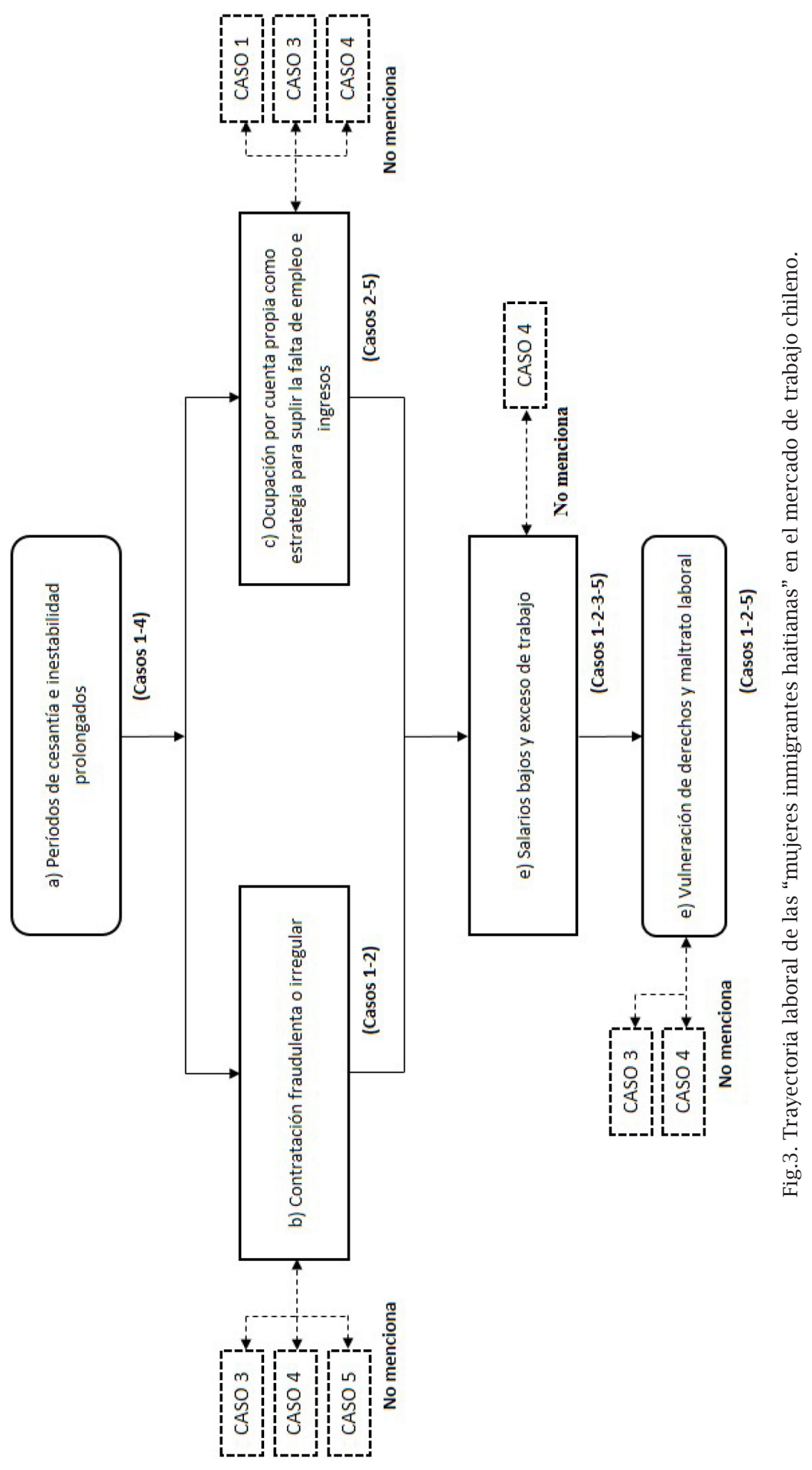


mayor, sin que ello remita un aumento en sus ingresos. En relación a la ocupación por cuenta propia, se observa que esta aparece como opción para suplir la falta de empleo y también puede ser una vía permanente en la que se establecen "redes con otras mujeres haitianas" para enfrentar en conjunto la escasez de trabajo propiamente formal.

En este contexto analítico, las ferias libres constituyen un "nicho laboral" que si bien exhibe ciertas condiciones de formalidad, también permite el establecimiento de todo tipo de actividades informales, promoviendo un circuito que puede ser por un lado ventajoso, pues está facilitando la formación de redes en este caso entre mujeres y por otro, desventajoso ya que ofrece la posibilidad de que migrantes trabajen como indocumentadas y permanezcan en esta situación, generando una marginalidad que aumenta las condiciones de pobreza y riesgo social de estas personas. Este proceso global, como puede verse en el diagrama expuesto, culmina evidenciando la existencia de una sistemática vulneración de derechos y maltrato laboral en el transcurso de la trayectoria laboral de "mujeres haitianas”, que no sólo revelan eventos de discriminación y racismo, sino que también esconden prácticas abusivas como la utilización “desechable” de mano de obra extranjera.

En relación a la identificación de los factores de desigualdad en el acceso al mercado del trabajo y otros bienes y servicios en el país de "acogida”, los elementos identificados no componen un proceso fluido que tenga inicio y término, sino que deben ser entendidos de forma integral como implicancias que están a la base de las opresiones vividas por "grupos subordinados”. En el relato de las entrevistadas, se presentan varios elementos que para ellas dan origen a una posición desventajosa en el ámbito laboral y afectan su proceso de inserción y trayectoria. Es preciso indicar que los cinco factores detectados, ponen en evidencia la realidad puntual que viven estas "mujeres haitianas", el hecho de que este escenario pueda ser extrapolable al colectivo de mujeres haitianas en general, tendría que ser una tarea posterior de investigación más profunda. Los componentes que estas mujeres vivencian dicen relación con: la nacionalidad, en este punto destaca lo señalado por el Caso 1 quien se enfrenta a diversas situaciones incluidas actitudes de racismo y discriminación, las que atribuye a su procedencia territorial, de la cual está orgullosa y es enérgica en plantearlo. Otro factor es la irregularidad migratoria, la complejidad de obtener un visado de trabajo en Chile impide la concreción de sus proyectos y confunde a las mujeres, quienes arriban al país convencidas de que esta tarea será fácil, sin embargo la realidad las obliga a transitar un largo camino en el que sus posibilidades se ven limitadas por este hecho. Por otro lado, se detecta en la mayoría de casos, menciones reiteradas acerca de las condiciones habitacionales y económicas o de ingresos que para la "comunidad haitiana" son especialmente desfavorables. El alto costo de la vida en Chile, es un problema que ante la inestabilidad laboral y el trato diferenciado respecto a trabajadoras que sí pueden exigir mínimas condiciones amparadas en una relación contractual formal, está ocasionando el empobrecimiento de estas personas, tal suceso conlleva incluso tomar la decisión de extender su trayecto migratorio a otros destinos o pensar en regresar al país de origen, no obstante la falta de recursos hacen que esta nueva 
decisión implique mantenerse en Chile por más tiempo, soportando las malas condiciones. En este devenir, las estrategias que despliegan y el apoyo que se brindan, es central y muestra como estas mismas mujeres se responsabilizan y suplen la débil y casi nula intervención de los servicios públicos, auto-gestionando los recursos, la empleabilidad y la vivienda. Se observa que, condiciones económicas y habitacionales son percibidas como un obstáculo para su desarrollo, estos dos factores se relacionan directamente ya que el valor de la vivienda es alto para ellas, el financiamiento del hogar implica renunciar a compromisos económicos como cubrir la deuda del dinero invertido para ingresar en Chile o detener el envío de remesas, la forma más usual de sobrellevar esta situación es el "arriendo colectivo" de habitaciones o viviendas con espacios comunes. Finalmente, el idioma es otro factor que afecta y dificulta el proceso de inserción y trayectoria laboral de estas mujeres en Chile, algunas no pueden mantener trabajos por este motivo y otras manifiestan que el trato diferenciado del haitiano, se debe a que no habla español, además hay que puntualizar que muchas de ellas deben educarse en el idioma y esto retarda el inicio en la búsqueda de empleo.

\section{CONCLUSIONES}

Este estudio de caso explora una dimensión de los procesos migratorios, en la cual aún hay preguntas de investigación sin responder. En este contexto, los resultados que se han obtenido en este trabajo, muestran la urgencia de atender e intervenir en este ámbito, ya que es evidente que la migración haitiana está aumentando significativamente en Chile y con ello se configuran una serie de situaciones sociales que requieren de un pronunciamiento por parte del Estado. Dicho de otro modo, junto a los “nuevos Procesos migratorios" también emergen "nuevas realidades" y atributos socioculturales que son necesarios de considerar. Estos rasgos emergentes interpelan a las actuales políticas públicas e exigen integrar en su re-diseño acciones que promuevan y respondan integralmente a estas "realidades migratorias emergentes" en el mundo contemporáneo.

En el caso de "las mujeres haitianas" que fueron parte de esta indagación, hay que señalar que todas, tenían una situación relativamente estable en términos ocupacionales en Haití, a pesar de ello, deciden emigrar con el objetivo de mejorar estas condiciones previas, sin embargo una vez en Chile, sus proyectos sufren variaciones y son de difícil concreción. La realidad que viven en sus países de origen, termina replicándose en el país de destino. Hay que destacar el hecho de que ninguna de estas mujeres, ha podido brindarle a sus familias la estabilidad económica que buscaban, al contrario, pasan primero por un largo periodo de adaptación en el que familiares y amigos connacionales cumplen un papel fundamental en el proceso de asimilación que implica vivir lejos de sus hogares. Este es el único recurso con el que pueden contar a la hora de enfrentar su inserción en la sociedad chilena y particularmente, al mercado de trabajo. Este último brinda escasas oportunidades laborales y las opciones que existen, son de mala calidad y no les permiten regularizar su situación migratoria, quedando 
limitadas a dos posibilidades, desempeñarse en ocupaciones amparadas en una relación contractual sin validez formal, generalmente asociadas al servicio de aseo y cuidados o autogestionar su propia empleabilidad en actividades informales por cuenta propia, desempeñándose como comerciantes en "ferias o mercados locales" o prestando esporádicos servicios en sus áreas de conocimiento o saberes específicos, adquiridos en su país de origen o a través de procesos de aprendizaje informales en el país de "acogida". Algunas actividades identificadas son servicios relacionados con la estética como: peluquería, manicuristas, entre otros.

Diversos son los elementos que dan origen a una sensación desfavorable, al momento de insertarse laboralmente o encargarse del alto costo de vida que implica residir en Chile. Enfrentar situaciones de discriminación o racismo, son una experiencia más en la larga lista de factores que condicionan las desigualdades sentidas por estas mujeres. Componentes como el idioma, la situación migratoria, la nacionalidad, el acceso a la vivienda y las condiciones económicas o de ingresos se entrecruzan ubicándolas en una posición de subordinación y clara desventaja. Al respecto, se advierte la presencia de fundaciones eclesiásticas que se encargan de intervenir en esta área, operando más que nada como oficinas de colocación de empleo. En este sentido, hay que mencionar que la ausencia de intervención pública, abre la oportunidad para que instituciones del tercer sector se impliquen con esta realidad, abordando desde una lógica asistencial las necesidades y gestionando desde un punto de vista meramente económico la integración de estas mujeres, quedando fuera otras áreas no menos importantes, como podría ser la asesoría legal en casos de vulneración de derechos laborales o la constatación de situaciones de extrema pobreza y riesgo social.

\section{REFERENCIAS}

Acosta, E. (2011). Valorar los cuidados al estudiar las migraciones: La crisis del trabajo de cuidados y la Feminización de la inmigración en Chile. En Mujeres inmigrantes en Chile. ¿Mano de obra o trabajadoras con derechos? (pp. 193-228). Santiago de Chile: Ediciones Universidad Alberto Hurtado.

Anthias, F. (2006). Género, etnicidad, clase y migración: interseccionalidad y pertenencia translocalizacional. En P. Rodríguez (Ed.), Feminismos periféricos (p. 49-68). Granada: Editorial Alhulia

Anthias, F. (2012). Transnational Mobility, migration research and intersectionality. Nordic Journal of migration studies, 2, 102-110.

Brega, C., Durán, G., \& Benjamin Sáez, B. (2015). Mujeres trabajando. Una exploración al valor del trabajo y la calidad del empleo en Chile. Estudios de la Fundación Sol. Recuperado de: http://www.fundacionsol.cl/wp-content/uploads/2015/03/Estudio-MujeresTrabajando-2015.pdf

Cáceres, P. (2003). Análisis de contenido cualitativo: una alternativa metodológica alcanzable”. 
Psicoperspectivas Revista de la escuela de psicología. Facultad de filosofía y educación Pontificia Universidad Católica de Valparaíso, II, 53-82.

Cárdenas A., Correa N., \& Prado X. (2014). Segregación laboral y género: tendencias y desafíos relativos al mercado laboral de la salud y la educación en Chile. Polis, 38. Publicado el 08 septiembre 2014, consultado el 01 octubre 2016. URL: http://polis.revues.org/10182

Departamento de Extranjería y Migración (2015). Boletín informativo. Migración haitiana en Chile, Santiago: Ministerio del Interior y Seguridad Pública, recuperado de: http://www. extranjeria.gob.cl/media/2016/09/boletin-1.pdf

Hidalgo, M. (2014). La inserción laboral de la población migrante en Chile: barreras, tensiones y desafíos (Texto inédito). Ponencia-comentario a investigación "Integración laboral de los inmigrantes haitianos, dominicanos y colombianos en Santiago de Chile" Presentada el: 6 de octubre de 2014 .

Hochschild, A., R. (2001). Las cadenas mundiales de afecto y asistencia y la plusvalía emocional. En A. Giddens \& W. Hutton (Eds.), En el límite: La vida en el capitalismo global (pp. 161208). Barcelona: Tusquets Editores

Magliano, M. J. (2015). Interseccionalidad y migraciones: potencialidades y desafíos. Estudios feministas. Florianópolis, 23(3), 691-712.

Martínez Buján, R. (2010). La reorganización de los cuidados familiares en un contexto de migración internacional. Cuadernos de relaciones laborales, 29(1), 93-123.

Martínez, J. (2008). América Latina y el Caribe: "Migración internacional, derechos humanos y desarrollo”. Santiago de Chile. Santiago de Chile: Comisión Económica para América Latina y el Caribe CEPAL.

Novick, S. (2012). Migraciones en el Cono Sur: Políticas, actores y procesos de integración. En La construcción social del sujeto migrante en América Latina. Prácticas, representaciones y categorías (pp. 111-146). Buenos Aires, Quito, Santiago de Chile: CLACSO - FLACSO $\mathrm{UAH}$.

Parella, S. (2003). Mujer, inmigrante y trabajadora: la triple discriminación. Barcelona: Anthropos.

Parella, S. (2007). Las migraciones femeninas y la internacionalización de la reproducción social. Algunas reflexiones. Instituto Europeo del Mediterráneo IEMED, p. 65. Recuperado de: http://www.iemed.org/publicacions/quaderns/7/e149_Parella.pdf

Pérez Orozco, A. (2006). Amenaza tormenta: la crisis de los cuidados y la reorganización del sistema económico. Revista de economía crítica, 5, 7-37.

Rojas Pedemonte, N., Amode, N., \& Vásquez, J. (2015). Racismo y matrices de inclusión de la migración haitiana en Chile: elementos conceptuales e contextuales para la discusión. Revista Polis, 42, 217-245.

Sassen S. (2003). Contrageografías de la Globalización. Género y ciudadanía en los circuitos transfonterizos. Madrid: Editorial Traficantes de Sueños.

Sassen S. (2003). Los espectros de la globalización. Buenos Aires: Fondo de Cultura Económica 
de Argentina.

Stefoni, C., \& Fernández, R. (2011). Mujeres inmigrantes en el Trabajo Doméstico: entre el servilismo y los derechos. En Mujeres inmigrantes en Chile. ¿Mano de obra o trabajadoras con derechos? (pp. 43-72). Santiago de Chile: Ediciones Universidad Alberto Hurtado.

Thayer, E. (2011). Trabajo y Género: La condición social de inmigrante como referente para la definición de la identidad. En Mujeres inmigrantes en Chile. ¿Mano de obra o trabajadoras con derechos? (pp. 73- 108). Santiago de Chile: Ediciones Universidad Alberto Hurtado..

Verd, J. M., \& Lozares, C. (2016). Introducción a la investigación Cualitativa. Fases, métodos y técnicas. Madrid: Editorial Síntesis.

Valenzuela, P., Araya Morales, I., Campos, B., Palomo, N., Riveros, K., Salazar, C., \& Tavie, C. (2014). Integración laboral de los inmigrantes haitianos, dominicanos y colombianos en Santiago de Chile. Revista Antropología del Sur, 2, 102-120.

Yuval-Davis, N. (2006). Intersectionality and Feminist Politics. European Journal of Women's Studies, 13(3), 193-209. 